with blood and mucus. He had no pain, and felt comfortable; the enema was repeated. 318t. The bowels had not been mored; he felt more comfortable in every respect. The reports from this date tell of his gradual recovery."

The author then states in his remarks : "The muco-enteritis, I believe, arose from a combination of causes : from the use of the aperients; from the specific action which mercury has upon the bowels of some individuals on its introduction, however slightly, into the system. The markedly beneficial influence of the opium throughout the case especially deserves notice, adding as it does to the evidence in favour of its use in strangulated hernia, and in abdominal injuries and diseases generally. Most recent writers in the after-treatment of cases of herniotomy advocate the propriety of conceding rest to the bowel to enable it to recover the injury which its structure or function may have sustained, and this, not only by abstaining from the use of aperients, but by administering opium to accomplish it. The duration of this repose will vary of course with individual cases, and will depend upon whether the patient has been brought under its influence during the trial of the taxis. In the present case, the patient continued drowsy after the operation was completed, and none was given until the biswels were relieved. Mr. Guthrie recommends that one grain should be given two or three times a day, according to its effect, for the first two days, and be followed up by a large emollient enema at the expiration of that time. I coniess that I was not sufficiently delivered from the trammels with which the long inculcated orthodoxy of the aperient treatment had entwined me, to wait so long, but when the vomiting and pain that occurred on their administration supervened on a hitherto favourable condition, I repented of my adherence to past teaching, and resolved in future cases to adopt that plan unhesitatingly, which modern science has shown to be the most rational, and modern experience the nost successful treatment."

Did time admit, I could say much more in farour of the passive plan of treatment after the operation for hernia. I am convinced that the administration of purgatives within the first twelve hours after the operation is not only unnecessary, but absolutely dangerous; and I have not the least doubt there are gentlemen present who have witnessed the beneficial effects of the former mode of treatment, and the deplorable results of the latter. In conclusion, permit me to observe that I am well aware I must yield to many present in point of opportunity and ability to treat this practical subject in the manner that its vast importance demands; but I will yield to no man in the sincerity of $m y$ intentions. The few imperfect remarks that $I$ have made are intended for comparison with the experience of others in the great field of practical surgery.

The life of one man is too short for him to do much towards advancing his profession as a science, but much may be done by comparing notes, for by this means the healing art may be placed upon a surer basis ; and should my humble efforts in the least degree assist in promoting this much desired result, my labour will not have been in vain, or your time needlessly wasted.

Spalding, June 1854.

\section{INQUIRY INTO THE PROPRIETY OF OPENING THE BOWELS SOON AFTER THE OPERATION FOR STRANGULATED HERNIA.}

\section{By JOSEPH SAMPSON GAMGEE, Esq.}

Thodar, from the days of Franco, the most renowned surgeons have specially studied all matters relating to herniaso much so, indeed, that the reputation of sereral of the most illustrious among them is mainly based upon those investigations, and that more may be said to be known of this disease than of any other in the whole range of surgerythere are yet some important points upon which opinion is divided.

Having already submitted to the profession, in the pages of this periodical, a few considerations upon therdativemeciti of the intra-and extra-peritoneal methods of herniotomy, a rexed question of great practical moment, - I shall endear vour to contribute to the solution of another no less disputed and momentous question: Is it advisable, where they do not act spontaneously, to open the bowels soon after the operation for hernia; or is it, on the contrary, desirable to favour the quietude of the alimentary canal?

This question has often perplexed me in watching cases of hernia: and the perplexity has been only augmented in my endeavours to remove it, by consulting the opinions of the most renowned surgical writers. One line of practice is insisted on by Louis, Samuel and Astley Cooper, Hey, Lawrence, Richter, Velpeau, and Syme; a totally opposite one by Dupuytren, Liston, Miller, Hancock, and others. Velpeau strenuously recommends purgatives after the operation for their power in preventing inflammation: their undoubted tendency to excite and aggravate it is the reason which Dupuytren alleges for objecting to them. The propriety of early administering them is regarded by Mr. Lawrence as one of the most unequirocal results of experience and the plainest dictates of common scnse: Mr. Hancock insists that the most unequirocal results of experience, and the plainest dictates of common sense, no less than doctrine, prove the injurious effects of purgative medicines after the operation for strangulated hernia.

Considering the great experience of the men who have defended each side of the question, and the certainty that the very opposite practices which they enjoin must in particular cases be productive of mischief, it becomes interesting to inquire in to their respective claims to assent, by an examination of the reasons and facts they adduce in their support.

Professor Miller teaches, that "after successful reduction by operation, the same treatment is required as in the case of simple taxis.... bland enemata, but no purge by the mouth, however simple, until many hours have elapsed; otherwise dilatation with obstruction will take place above the palsied portion of intestine, and the patient will probably sink under the symptoms of ileus."* Since dilatation with obstruction of the palsied portion of intestine is, to a greater or less extent, the condition par excellence of every patient whose bowels have not acted after his being the subject of strangulated hernia, there is no need of purgatives to induce it; the only question can be whether they would aggravate it: theoretically, we do not see how they can do so; and, practically, we know that they almost always succeed in speedily removing the obstruction,-reduction, I presume, of course, to have been effected prior to their administration. If in such cases purgatives exercise an injurious influence, it must be of altogether an opposite character to that attributed to them by Professor Miller; by so much stimulating the intestinal functions as to excite or aggravate already existing inflammation, or by determining the rupture of an ill-conditioned piece of bowel. So far from sharing the fear of the Edinburgh professor, Vidal, after remarking that many surgeons, influenced by theoretical preoccupations, have too exclusively condemned the use of purgatives after the operation ? $r$ hernia, states that he has with great benefit had recourse to the exhibition of croton-oil to overcome the excessive sluggishness of the bowels in some old subjects. It must be observed, howerer, that Vidal expresses himself dogmatically, and adduces no reasons or sufficient facts in defence of his own, and in condemnation of the opposite practice. $\dagger$

For precisely the same reasons as Mr. Miller interdicts purgatives, Richter and Louis recommend them. "If the strangulation," to use Richter's words, "depend upon an impaction of fæces, the intestines are so weakened after the operation as not to be able to clear themselves of their contents, which are a source of irritation to them, and interfere with the patient's well doing. Small doses of Epsom salts and clysters speedily produce an evacuation, and got rid of the unpleasant symptoms." +

- Practical Surgery, 2nd edit., p. 364.

+ Traité de la Pathologie Ext. et de Méd. Opératoire, rol iv, p. 189.

† Trattate delle Ernle. Prims Traduzzione Italiana, Milano, I002, p. 188. 
Iouis' opinion may be gleaned from a series of reflections on the operation for hernia, which he published in the Yemoirs of the Parisian Royal Academy of Surgery (8vo. edit., vol. xi). In a case in which he operated for bubonocele with urgent symptoms, he prognosticated farourably, from with urgent symperation having presented no unusual difficulty, and the gut being in good condition; yet the man died in less than twenty-four hours, with the symptoms of strangulation unmitigated.

On post mortem examination, the intestines were found filled with fluid between the stomach and the seat of strangulation, and the large intestines were filled with a largequantity of very hard fæces. The patient had refused enemata before and after the operation. From the good condition of the portion of gut contained in the sac, Louis infers that if the fæcal matters had been expelled by a mild purge, the patient would have been saved. After citing another case in point, he concludes (Op. cit. p. 491): "These examples suffice to illustrate, on the one hand the danger entailed by the omission of purgatives after the operation, and, on the other, the advantages accruing from them. It has therefore been improper to omit mentioning them, in the majority of works destined to the instruction of young surgeons: if enemata do not adequately fulfil the urgent indication, recourse must be had, and promptly, to laxative drinks."

In his most recent publication Mr. Liston directs, that after the operation for crural bernia, " the bowels should be allowed to rest quiet, no nhysic being administered of any kind." * Six years previously he taught, that after crural as well as after inguinal hernia, "large mild enemata are to be administered, and after some hours purgatives, so as to procure copious and free evacuation of the bowels." + It is remarkable that he should have given no reason for the change in his opinion upon this important practical matter; particularly as the change brought him into opposition with the teaching of an eminent authority, whom no one perhaps knew better how to appreciate than Mr. Liston; I allude to his friend Mr. Syme, who recommends "that if eracuation of the bowels does not occur spontaneously within three or four hours after the operation, it ought to be gently elicited by giving a table spoonful of castor-oil, which may, if necessary, be followed by the injection of a mild enema." t

Baron Dupuytren believed, according to the expression of the editors of his Leçons Orales, $\S$ that when the constricting cause has been removed, and the hernia reduced, only the inflammation of the intestines can, by suspending the peristaltic movement, be opposed to the re-establishment of fæcal evacuations; and that stimulant enemata or purgatives, administered under these circumstances, even though they succeed in promoting the evacuations, must inevitably tend to increase the inflammation, and favour the development of enteritis and peritonitis-that is to say, of the most formidable complication, which is the almost invariable cause of death after herniotomy, and against which every curative effort should be directed. It is a knowledge of these facts which induced M. Dupuytren to prefer antiphlogistics and depletives, to stimulants and purgatives. 'The very foundation of the baron's reasoning is an unfounded assumption: "Only," he says, "the inflammation of the intestines can, by suspending the peristaltic movement, be opposed to the re-establishment of the fæces:" but any one who has opened a considerable number of bodies within two or thrce days after the operation for hernia, cannot fail to have met with several cases in which the fæcal course had not been re-established, and in which no, or scarcely any, inflammation appeared on dissection; but the precise limits of the portion of gut that had been contained in the sac were unmistakably pointed out by the circular depressions in its coats; and whereas the distal bowel was very small, empty, and pale, that between the seat of stricture and the gut was big, venously congested, flabby-looking, and filled with fluid and

- Practical Surgery, 1846, p. 560.

+ Elements of Surgery, 1810 , p. 532

- Principles of Surgery, p. 318

Ifecons Orales de Clinique Chirurgicale, rol. jii, p. 261. solid frces. In such a case, debility from long-continued inaction and mechanical constriction is manifestly the cause that has impeded the intestinal function; the local exhaustion of intestinal function has been so great, that removal of the cause has not proved a sufficient remedy: a removal of the cause to set the bowel in action and unload itself. But, for the sake of argument, admitting the baron's assumption, that inflammation is the only cause which can prevent the bowels from acting, the reasons he adduces for excluding purgatives from the after-treatment are not admissible. He prefers antiphlogistics and depletives to stimulants and purgatives. But thus classing purgatives with stimulants, he begs the whole question. The point at issue is preciscly whether purgatives may or may not be antiphlogreciscly wh depletives under the circumstances? The accumulated faces must be a very powerful irritating cause, their removal must per se have an antiphlogistic effect, and the large amount of secretions forced out by the mucous membrane may fairly be supposed to do some good in unloading the engorged vessels. But far from sustaining in general terms that a purgative in enteritis acts as an antiphlogistic and depletive, I suggest that it does exercise those agencies, to a greater or less extent, when given to patients labouring under enteritis after the operation for strangulated hernia, and in whom, the bowels not having been relieved, facal accumulations and the non-re-establishment of the intestinal functions cannot but act as an incentive to inflammatory action. On this head, however, doubts may be raised: but even supposing the opposite to be provedthat in such cases purgatives tend to augment the inflammation-Dupuytren's arguments would only apply to those cases in which peritonitisand enteritis already exist. Happily, however, the number of cases of hernia operated upon before they supervene is considerable; and in solving the question whether purgatives should be administered to them or not, his arguments do not certainly apply with much force; in such cases the antiphlogistic and depletive effect of evacuating the bowels cannot fairly be doubted. The teaching of M. Dupuytren on this head is far too much in accordance with the doctrine of his brilliantly talented but too speculative contemporary, M. Broussais, to deserve much attention, opposed as it is to the opinions, founded on experience, of Velpeau and Lawrence.

M. Velpeau thus comments upon Dupuytren's teaching in this matter. "At first sight one is struck with the weight of his reasoning, though at bottom it be easy of refutation. In point of fact, the matters accumulated in the intestine are a powerful cause of inflammation. Now, the best means of extinguishing or of preventing the inflammation is to expel the foces. In this way purgative enemata and drinks exercise a power which no one can call into question. At the hospital of Tours I have seen M. Gouraud operate on a large number of herniæ, giving a purgative to all his patients immediately afterwards; and nowhere, so far as I am aware, has greater success been witnessed. $M$. Boyer, who appears to follow the same custom, has the reputation of being very successful in these operations.". M. Velpeau enjoins, "that if the bowels do not act spontaneously. after two or three hours, a simple enema should be given. In case of its failing, it may soon be followed by another, of somewhat more stimulating nature. If, after twelve hours, the evacuations had not commenced, it would be necessary to have recourse to purgative enemata with decoction of senna. Many practitioners are in the habit of exhibiting simultaneously a mild purgative by the mouth."*

Opposed to Dupuytren, Liston and Miller, andagreeing with Louis, Richter, Boyer, Syme and Velpeau, is Mr. Lawrence. In the operation for strangulated hernia, we find:-"When the operation is finished, the patient should be placed in bed and allowed to remain there quictly for some time, a little thin gruel or diluent being given, if it is desired. The pain is lessened and the vomiting ccases after the operation; sometimes the bowels are spontaneously relieved, and a considerable abate-

- Nouveaux Elémens de Xédecine Opératoíre, tome ii, p. $\$ 99$. 
ment of the symptoms generally ensues. More commonly it is necessary to solicit the action of the intestinal canal by aperients and injectious. If, therefore, the bowels should not have been relieved in three or four hours, a few grains of calomel may be given in a pill; or two pills may be administered, consisting of calomel and the compound extract of colocynth in equal parts. The sulphate of magnesia may be given afterwards in a diose of two drachms, or of one drachm, in the infusion of roses, or in a mixture of mint water and common water; and this should be repeated every three or four hours until the bowels are freely relieved. If this desirable result should not occur before the second dose, a large common injection should be thrown up, with the addition of four or six ounces of infusion of senna, or an ounce of castor oil. We must repeat those or similar means, and persist in their employment, until the canal is completely unloaded; remembering that the intestines frequently contain a large collection of faecal matter and of morbid secretions, which can only be got rid of by several copious motions, and that the operation of purgatives must be salutary, not merely by removing this noxious accumulation, but by exciting a discharge of fluids calculated to lessen inflammatory action. 'The notion that purgatives are capable of exciting the mucous membrane of the alimentary passages, and thus of producing or agrravating inflammation of the stomach or bowels, and the prohibition of their employment on this account both after the operation for strangulated hernia and in many other cases, is in my opinion entircly groundless; and the practical precepts, founded upon this theoretical and imaginary foundation, have always appeared to me a signal triumph of doctrine over the most unequirocal results of experience and the plainest dictates of common sense."* Thus Mr. Lawrence, whose Treatise on Hernia, published in the early part of the present century, is admitted by surgeons of all countries to be one of the most valuable contributions ever made to surgery, has, in a fifth edition, after deroting ncarly half a century to very extensive practice, a great part of which has been in the largest hospital of London, insisted on the propriety of opening the bowels early after the operation, and characterised as entirely groundless the reasons adduced against that practice.

The opinions hitherto quoted must rather be regarded as reminiscences of the practice of their respective authors, than as precise conclusions deduced from analysis of recorded facts. Rather than satisfy all desire for information on the subject, they suggest the desideratum of a statistical inquiry as the only means of definitively settling the question. Such an inquiry has been undertaken by Mr. Hancock $t$ t and from an analysis of 432 cases, he has inferred that purgatives after the operation for strangulated hernia do harm. In support of his opinion, he alludes to cases in which, though the bowels have been allowed to remain torpid several days after the operation, recovery has taken place. No one denies such cases; experience furnishes many, and apart from it we should suppose them to be numerous; but they do not affect the question, whether or no in another class of cases opening the bowels may not do good, and avoiding doing so be productive of harm. Cases of hernia differ so rery widely, that we cannot apply to some the reasoning deduced from others, without considering all modifying circumstances. A hernia may become strangulated just after a patient has had a copious motion, and a dozen hours may elapse before relief is afforded. Supposing the operation needed, it is performed, and the gut may be found in a very good state. If additionally the general health have suffered little, it is perfectly clear that there would not be much fear of mischief, even though this person's bowels were not opened for a wcek; but would the result in this case afford any just ground for anticipating the same result from similar treatment in a case differing from the above in almost every important particular? If the illustrious Morgagni, in an excess of zeal for accurate study,

- Treatige on Ruptures, 5th ed. p. 322.

+ Observations on Hernia, 1850, pp. $72-80$. erred in exclaiming, "Observationes perpendevdae non numerandae, the fundamental truth of the great idea which guided him in the execution of his stupendous work cannot be questioned. The first step towards generalisation is to weigh the individual facts, a process to which those accumulated in Mr. Hancock's table have not been submitted. When it is borne in mind how greatly the results in hernia are influenced by numerous circumstances, before, during, and after the operation, only limited value can be attached to conclusions deduced as to the influence of one circumstance irrespective of an accurate estimation of all the others, opposed as it is to the teaching of Louis, Richter, Velpeau, Lawrence, and Syme. Truly, it is in consonance with the opinions of Dupuytren and Liston; but that of the former, from its fallacious theoretical foundation, does not merit the respect which the great name of its author inspires; while the value of that of the latter is seriously lessened by its being in direct opposition to what Mr. Liston himself taught a few years previously, and not supported by a statement of the reasons which induced the change.

The weight of authority is against the two last named surgeons and their followers. To this fact, however, any one acquainted with the history of similar discussions will justly attribute only a qualified value. How often have a comparatively small number of facts, collected by one or a very few men, subverted dogmatic teaching which had not been called in question for ages. There can be no doubt but that such instances will multiply in proportion as facts are observed nore correctly. But there is one reason why the testimony of the majority in the present instance deserves especial attention. Louis, Lawrence, Velpeau, and their followers, who recommend purgatives because they may do good and can do no harm, have had the opportunity in an inmense number of cases to test the propriety of such practice; but Dupuytren, who on doctrinal grounds alone opposes purgatives, cannot have had much opportunity of testing their effects, for he abstained from using them. Mr. Liston, it is true, having held both doctrines and pursucd both lines of practice, deserves more consideration; but I have already stated reasons why his opinion on this matter cannot be admitted as decisive.

To determine the merits of these two opposite lines of practice, a very extensive experience on this particular subject is needed; more extensive and accurate than is perhaps recorded in the note-books of any individual surgeon. I have observed both, in a very considerable number of cases; but so very various are the conditions of strangulated hernix, that a much larger number than I possess is indispensable for the basis of an analysis adequate to the solution of the problem. I have never seen harm result from the exhibition of an enema, containing from one to two ounces of oil, shortly after the ojeration. When this has not been followed by an evacuation, I have seen it induced with relief to the patient by a mild purge. I have repeatedly seen patients in whom the bowels did not act spontaneously after the operation relieved from a state of general yreasiness, so soon as means were adopted to promote an evacuation. It is important to notice that, in none of my cases in which purgatives were prescribed, was there at the time sevcre inpurgatives were pren from the appearance of the gut at the the time of operation, for fearing its disorganisation. One light which these observations afford, enables me to appreciate in great measure the merits and defects of the two practices in question, and to arrive at as near an approach to the truth as is at present possible.

The various conditions in which we find cases of hernia at the time of operation, admit of their arrangement under four heads. 1. Those cases in which the intestine is in good four heads. 1. Those cases in which the intestine is in mot yet manifested itself 2. Those in which, though the bowel is in very fair condi2. Those in which, though the bigns of a moderate amount of peritonitis; 3 . Those in which the bowels are notably discoloured, but of good consistence; peritonitis being intense; 4. Those in which there is threatening gangrene of the gut. 
Let us consider the first class of cascs. Since it is reasonable to suppose that in a case of strangulated hernia that has been operated upon, a part at least of the uneasiness dependent upon the intestinal function is immediately due to its restoration, we should in this class of cases theoretically be disposed to promote the action of the intestines, when it does not occur spontaneously, a short time after the constriction has been removed. Such practice seems the more reasonable, in that there can be no fear of aggra rating inflammation which does not exist, and in that there is reason to believe that the expulsion of the accumulated faces is tantamount to the exclusion of a possible, if not probable cause of inflammation.

In the second class of cases, the first part of the argument used above applies, but not the second; for inflammation exists, and the question arises, whether the adninistration of purgatives, theoretically indicated by the necessity of restoring the intestinal functions, may not be productive of evil by aggravating the inflammation. From what I have seen, however, these fears would not disquiet me. I think there is more chance of the progress of inflammation bcing checked by the expulsion of the irritating faces, and restoration of the gut to its function, than of its being aggravated by the stimulant action of the purgative.

In the third class of cases, in which the bowel is in moderate condition, but the peritoneum intensely inflamed, it is reasonable to believe that the constipation, although in great measure dependent upon the atony which has resulted from long inactivity, is likewise due to the disturbance of invervation incident upon the inflammation. It seems hence prudent to respect the objections of those who allege that the inflammation may be aggravated by purgatives; but while antiphlogistics are being actively employed, there is no reason for objecting, if the bowcls do not act, to enemata; the probabilities of their doing good are much greater than those of their possible perniciousness.

In the fourth class of cases (threatening gangrene of the intestine), inasmuch as there is more to fear from the action of the intestines, though it be but moderate, than from their inactivity, though it be extreme, enema and purgatives appear contra-indicated so long as there is reason to fear disorganisation of the gut.

From the foregoing considerations flow three rules for practice, in cases in which the operation of herniotomy is not followed by spontaneous action of the bowels.

1. When the condition of the gut is good, and there is little or no peritonitis, an oleaginous enema should be given an hour or two after the operation, and repeated after three or four hours in case of failure, or a purgative exhibited by the mouth.

2. When the peritoneal inflammation is intense, even though the bowels be in fair condition, antiphlogistics must be perseveringly employed; and though a simple enema may be given in the first six hours, it is inadvisable to excite the action of the bowcls until the next day, either by more active enemata or purgatives by the mouth.

3. In the case of mortification threatening the gut, the bowels should be kept quiet by opium, and purgatives and enemata abstained from until the danger of perforation has passed.

These rules promise to be faithful guides for practice, inasmuch as they are in conformity with sound doctrine, and, so far as I am aware, opposed by no facts; but the great rule is, to observe rigorously the symptoms of each particular case, to study its indications and aid nature with the lights which doctrine and practice reflect, and not to pretend to act according to systematic rules based upon speculations, in cases which present infinite varieties, according to the age and constitution of the patient; the duration, size, and position of the hernia ; the degree and duration of the strangulation; the condition of the intestine; the presence or absence of inflammation; and other more or less important conditions. In truth, just as there is reason for dissenting from those who systematically oppose purgatives after herniotomy, there is reason for not placing implicit faith in the teaching of those who universally recommend them. If there be any class of cases in medicine and surgery-and there are many-in which systems are injurious, and in which each case requires to be studied of itself with the light of reason and experience, that class is preeminently the one which comprises cases of strangulated hernia.

Palazzo Corsi. Florence, Juue 18ist.

\section{ANEURISM OF THE LEFT EXTERNAL CA-} ROTID ARTERY : SUCCESSFUL LIGATURE OF THE COMMON CAROTID.

\author{
By GEORGE MITCHINSON, Esq
}

[Read at the Annual Meceting of the Midland Branch of the Procincial Medical and Surgical Association, at Lincoln, June 1st, 1854.」

Tue following ease presents several points equally of interest to the physiologist and to the practical surgeon.

Cast. William Bellamy, aged 48 , by trade a carpenter, living in the country, an active well proportioned man, of sober habits, always enjoyed good health until ten years aro $(18+1)$, when he suffered from pain in the head and slight deafness. About this time, he also occasionally raised a little sputum streaked with blood; this, however, entirely ceased during the summer. The deafness increasing, he consulted his medical attendant, who informed him that he was suffering from polypus, and proposed extraction; but this he declined.

A few months afterwards, he noticed a fulness under the left ear, accompanied by throbbing sensations along the neck, aud an occasional discharge (from the ear) of pus mixed with blood.

The fulness in the neck increased very slowly until March 1850 , when a sudden gush of bright blood took place from the ear, after unusual cxcrtion; it was followed by twitching of the face and left eyelid. From this time, the tumour increased more rapidly, and slight bleeding from the ear occurred almost every day; it sometimes amounted to a few drops, but occasionally, the patient stated, to as much as a tablespoonful. This was always followed by twitching of the face and difficulty of articulation.

July 16th, 18:00. The patient consulted Mr. Hewson, who, on cxamination, found an aneurism of the left external carotid artery, extending from the external meatus to below the angle of the lower jaw. The mouth was drawn to the right side; the patient was unable to close the left eyc; the tongue was flattened by pressure against the teeth of the left side, and, when put out of the mouth, protruded to the left side. Articulation was indistinct, though rapid. The general health was good.

July 19th. Great and sudden enlargement of the tumour having taken place, Mr. Hewson determined upon tying the common carotid artery. Chloroform having been administered, the patient was placed with the neck raised, and the face turned to the right side. An incision was made through the integuments, along the inner side of the sterno-mastoid muscle, terminating at its attachment to the sternum. The fascia and cellular tissue were then divided; this rendered visible the border of the sterno-hyoid muscle. Crossing the upper angle of the wound was the omo-hyoid. The sides of the wound being held apart, the sheath of the vessel was carefully scratched through, and the artery cxposed. A ligature was then passed under the artery, and firmly tied; and the edges of the wound were brought together by slips of plaster and sutures, and covered by wet lint. Very little blood was lost during the operation.

July 20th. He slept three or four hours in the night. The countenance was tranquil; the pulse regular, 76, of moderate volume. The tongue was moist, rather white. The tumnur had decreased in size.

July 21 st. The patient had no pain. The pulse was 72 , soft, and compressible. The bowels had not been open. A simple aperient was ordered.

July 22nd. The bowels had been open twice. The pulse was 72 ; the tongue was clean. Slight oozing had taken 